\title{
A modified Bilirubin-induced neurologic dysfunction (BIND-M) algorithm is useful in evaluating severity of jaundice in a resource- limited setting
}

Paula G Radmacher ${ }^{1}$, Frank D Groves ${ }^{2}$, Joshua A Owa ${ }^{3 *}$, Gabriel E Oforwe ${ }^{4}$, Emmanuel A Amuabunos ${ }^{5}$, Bolajoko O Olusanya ${ }^{6}$ and Tina M Slusher ${ }^{7,8}$

\begin{abstract}
Background: Severe neonatal jaundice with associated acute bilirubin encephalopathy occurs frequently in low- and middle-income countries, where advanced diagnostic technology is in short supply. In an effort to facilitate the physical diagnosis of acute bilirubin encephalopathy, we pilot-tested a modified bilirubin induced neurologic dysfunction scoring algorithm in a group of pediatric trainees (residents) and their mentors (consultants) in a resource-constrained setting.

Methods: Jaundiced Nigerian infants were examined by consultant and resident pediatricians. The modified bilirubin induced neurologic dysfunction score assigned by residents was compared with the clinical diagnosis of acute bilirubin encephalopathy by expert consultants. Demographic information was obtained. Known risk factors were also evaluated among infants with and without acute bilirubin encephalopathy in addition to exploratory analyses. Data were analyzed by Statistical Analysis System; statistical significance was set at $\mathrm{p}<0.05$.

Results: Three hundred and thirty three paired modified bilirubin induced neurologic dysfunction scores (333) were analyzed and showed excellent agreement (weighted Kappa coefficient 0.7969) between residents and consultants. A modified bilirubin induced neurologic dysfunction score greater than or equal to 3 was highly predictive of a clinical diagnosis of acute bilirubin encephalopathy, with sensitivity of $90.7 \%$, specificity of $97.7 \%$, positive predictive value of $88.9 \%$, and negative predictive value of $98.2 \%$. Exposure to mentholated products was strongly associated with increased risk of acute bilirubin encephalopathy among those with known glucose-6-phosphate dehydrogenase deficiency (odds ratio $=73.94 ; 95 \%$ confidence interval $=5.425$-infinity) as well as among those whose G6PD phenotype was unknown (odds ratio $=25.88 ; 95 \%$ confidence interval $=2.845-235.4$ ).

Conclusions: The modified bilirubin induced neurologic dysfunction score for neonatal jaundice can be assigned reliably by both residents and experienced pediatricians in resource-limited settings as reflected in the algorithm's sensitivity and specificity. It may be useful for predicting the development and severity of acute bilirubin encephalopathy in neonates.
\end{abstract}

Keywords: Severe neonatal jaundice, Acute bilirubin encephalopathy, Evaluation of BIND score

\footnotetext{
* Correspondence: jaowa2001@yahoo.co.uk

${ }^{3}$ Department of Paediatrics and Child Health, Obafemi Awolowo University, Ile-lfe 220005, Nigeria

Full list of author information is available at the end of the article
}

\section{Biomed Central}

(c) 2015 Radmacher et al.; licensee BioMed Central. This is an Open Access article distributed under the terms of the Creative Commons Attribution License (http://creativecommons.org/licenses/by/4.0), which permits unrestricted use, distribution, and reproduction in any medium, provided the original work is properly credited. The Creative Commons Public Domain Dedication waiver (http://creativecommons.org/publicdomain/zero/1.0/) applies to the data made available in this article, unless otherwise stated. 


\section{Background}

Worldwide, neonatal jaundice (NNJ) is one of the most common conditions requiring in-patient treatment in the early postnatal period [1-3]. Successful early detection and postnatal treatment procedures before and after hospital discharge have made the potentially lethal neurotoxic effects of severe neonatal jaundice a rare occurrence in the industrialized world $[4,5]$. For instance, it is unusual to treat neonatal jaundice beyond phototherapy except in a few extreme cases when exchange blood transfusion (EBT) may be required to quickly reduce the circulating unconjugated bilirubin concentrations and prevent the movement of free bilirubin into the brain tissues.

In resource-limited settings however, neonatal jaundice continues to be a major cause of neonatal mortality as well as morbidity, characterized by acute bilirubin encephalopathy (ABE), and later, kernicterus in the form of auditory neuropathy and chorioathetoid cerebral palsy, and mortality [6]. In Nigeria where the burden of neonatal jaundice is exceptionally high, many infants are born at home or church clinics, and may die before ever seeing a physician or other health care workers $[7,8]$. Neonatal jaundice is often not easily appreciated by mothers and caregivers in the home setting until it becomes severe enough to deeply discolor the sclera and the skin, at which point neurological damage may have already occurred. Additionally, a considerable number of infants arrive at the hospital or health care facility only after irreversible bilirubin encephalopathy has occurred [8]. In a recently published survey, only $51.5 \%$ of community health workers in southwest Nigeria gave a correct definition of neonatal jaundice, and only $45.5 \%$ correctly identified danger signs [9]. Even trained medical professionals may miss the clinical signs and features of $\mathrm{ABE}$, especially in the early stages, so that appropriate intervention for infants with reversible brain injury may be delayed $[10,11]$. Thus there is a need for a tool that clinicians can use to recognize the danger signs of $\mathrm{ABE}$ early enough when appropriate intervention is most likely to lead to limiting or reversing adverse neurodevelopmental outcomes.

In resource-limited settings where the diagnosis of $\mathrm{ABE}$ is commonly made without magnetic resonance imaging (MRI) or auditory brainstem response (ABR) confirmation, experienced pediatricians are adept at recognizing this constellation of signs. However, attempts to quantify the prevalence of $\mathrm{ABE}$ and its severity across communities and among physicians with different levels of expertise were historically limited by the lack of a uniform diagnostic algorithm. In 1999, the bilirubin-induced neurologic dysfunction (BIND) scoring algorithm was developed, assigning 1, 2 or 3 points to indicate mild, moderate, or severe abnormalities in an infant's mental status, muscle tone, or cry (Additional file 1) [12]. Higher scores indicate worsening signs of acute neurotoxicity associated with excessive hyperbilirubinemia, providing a common descriptive framework for clinicians and researchers to estimate the severity of neonatal jaundice. The simplicity of the BIND scoring system, similar to the Apgar score, makes it an attractive tool for clinical diagnosis of $\mathrm{ABE}$ in resource limited locations that lack ready access to MRI) and ABR testing [13]. However, the practicality and acceptance of this scoring algorithm in such settings has not been reported. This study was therefore designed to evaluate the reliability and reproducibility of a modified BIND (BIND-M) scoring system within the scope of the routine newborn examination in Nigeria when used by both trainees and consultant pediatricians. Additionally, BIND$M$ scores were analyzed for utility in a subset of infants with recorded clinical signs and symptoms of varying degrees of jaundice.

\section{Methods}

\section{Human subjects}

This study was approved by the Institutional Review Boards (IRBs) at the University of Louisville USA, the University of Minnesota USA, the Obafemi Awolowo University Teaching Hospitals Complex, Nigeria, the Ladoke Akintola University of Technology Teaching Hospital, Nigeria and the University of Benin Teaching Hospital, Nigeria prior to its initiation.

\section{Modified BIND score}

With the permission of Drs. Lois Johnson and Vinod Bhutani, the authors of the original BIND scoring algorithm (Additional file 1), the investigators developed a modified BIND scoring algorithm (BIND-M), which incorporates abnormality of the upward gaze, another classic sign of bilirubin encephalopathy, with additional qualifiers (Additional file 2). The goal was to develop a more comprehensive score which would better discriminate degrees of BIND severity. In the new scoring system, the maximum total score for BIND-M is 12. A score of 1-4 was predicted to be indicative of mild $A B E$, which is generally considered to be reversible if treated promptly and aggressively. An intermediate score (5-6) was predicted to be indicative of moderate $\mathrm{ABE}$, which might be reversible with urgent and prompt bilirubin reduction. Even higher scores (7 and above) would likely indicate severe/very severe $\mathrm{ABE}$, probably representing irreversible brain damage in most infants.

\section{Data collection}

One of the authors (TMS) provided initial training in the BIND-M scoring system to the consultant pediatricians at the sites, who in turn trained the resident physicians. The BIND-M was then incorporated into the routine physical examination of jaundiced infants in the 
hospital nurseries by both resident and consultant pediatricians, who independently computed a BIND-M score for each of 333 infants. Regardless of the score, physicians also were asked to determine if they believed an infant had the signs and symptoms of $\mathrm{ABE}$, based on the total clinical picture.

The BIND-M score and clinical determination of $\mathrm{ABE}$ by the consultant pediatricians were considered to be the reference points for this study. The total BIND-M scores, as assessed by residents, were cross-tabulated against the total BIND-M scores as assessed by consultants. Additionally, resident and consultant findings for each major sub-score of the BIND-M (alterations in muscle tone, mental status, cry, and gaze) were separately cross-tabulated. For each cross-tabulation, interrater agreement was assessed using the weighted Kappa statistic, with $95 \%$ confidence intervals (CI), as computed using SAS PROC FREQ.

Descriptive and exploratory analyses were conducted using additional clinical variables where available, as well as known risk factors for neonatal jaundice (sepsis, fetomaternal blood groups incompatibility, G6PD deficiency, menthol exposure). Means of continuous variables were compared between infants with and without ABE using SAS PROC MEANS and PROC T-TEST. Statistical significance was set at $\mathrm{p}<0.05$. Odds ratios (ORs) for dichotomous and categorical variables, along with their 95\% confidence intervals were calculated using unconditional logistic regression (SAS PROC LOGISTIC). Discordance at the $\mathrm{A}, \mathrm{B}$, and $\mathrm{Rh}$ loci were evaluated simultaneously in a single mode. Likewise, menthol exposure was evaluated in the context of G6PD deficiency, such that infants who were neither enzyme deficient nor exposed to menthol were the "grand" referent group to which all others were compared.

\section{Results}

Inter-rater reliability of the BIND-M score: residents versus consultants

Inter-rater reliability of BIND-M between pediatric residents and consultant pediatricians was determined for 333 records (Table 1). The total BIND-M scores showed excellent agreement between residents and consultants, as confirmed by the weighted Kappa coefficient of 0.7969 (95\% CI, 0.7426, 0.8512). The sub-scores for mental status (Table 2a), muscle tone (Table 2b), and cry (Table 2c), likewise showed a high level of agreement, with weighted Kappa coefficients of 0.7692 (95\% CI: $0.6977,0.8407), 0.8430$ (95\% CI: $0.7809,0.9051$ ), and 0.8139 (95\% CI: $0.7321,0.8957$ ), respectively. Only the simple Kappa coefficient of 0.5802 (95\% CI: 0.4055 , 0.7549) could be computed for the gaze sub-score (Table $2 \mathrm{~d}$ ), since it can take on only two values: zero and three.

\begin{tabular}{|c|c|c|c|c|c|c|c|c|c|c|c|c|c|c|c|}
\hline \multicolumn{2}{|c|}{ BIND-M score } & \multicolumn{14}{|c|}{ Consultants } \\
\hline & & 0 & 1 & 2 & 3 & 4 & 5 & 6 & 7 & 8 & 9 & 10 & 11 & 12 & Total \\
\hline \multirow[t]{14}{*}{ Residents } & 0 & 236 & 11 & 4 & 1 & 0 & 0 & 0 & 1 & 0 & 1 & 0 & 0 & 0 & 254 \\
\hline & 1 & 8 & 7 & 1 & 0 & 0 & 0 & 0 & 0 & 0 & 0 & 0 & 0 & 0 & 16 \\
\hline & 2 & 3 & 2 & 1 & 1 & 0 & 1 & 0 & 0 & 0 & 0 & 0 & 0 & 0 & 8 \\
\hline & 3 & 0 & 1 & 1 & 1 & 0 & 0 & 1 & 0 & 0 & 1 & 0 & 0 & 0 & 5 \\
\hline & 4 & 0 & 0 & 0 & 1 & 0 & 1 & 0 & 1 & 0 & 1 & 0 & 0 & 0 & 4 \\
\hline & 5 & 1 & 0 & 0 & 0 & 0 & 1 & 0 & 1 & 0 & 1 & 1 & 0 & 0 & 5 \\
\hline & 6 & 0 & 0 & 1 & 0 & 1 & 1 & 2 & 0 & 0 & 0 & 0 & 1 & 0 & 6 \\
\hline & 7 & 0 & 0 & 0 & 0 & 1 & 1 & 0 & 2 & 0 & 0 & 0 & 0 & 0 & 4 \\
\hline & 8 & 0 & 2 & 0 & 0 & 0 & 1 & 0 & 1 & 3 & 1 & 2 & 2 & 0 & 12 \\
\hline & 9 & 0 & 0 & 0 & 0 & 0 & 0 & 0 & 0 & 0 & 2 & 1 & 0 & 0 & 3 \\
\hline & 10 & 0 & 0 & 0 & 0 & 0 & 0 & 0 & 0 & 1 & 2 & 2 & 0 & 0 & 5 \\
\hline & 11 & 0 & 0 & 0 & 0 & 0 & 0 & 0 & 0 & 3 & 0 & 0 & 5 & 0 & 8 \\
\hline & 12 & 0 & 0 & 0 & 0 & 0 & 0 & 0 & 0 & 0 & 0 & 0 & 1 & 2 & 3 \\
\hline & Total & 248 & 23 & 8 & 4 & 2 & 6 & 3 & 6 & 7 & 9 & 6 & 9 & 2 & 333 \\
\hline
\end{tabular}

Weighted Kappa $=0.7969$ (95\% Cl: 0.7426, 0.8512).

The consultant deemed 53 (15.9\%) of the 333 infants to have ABE. Total BIND-M scores were evaluated for clinical utility in diagnosing ABE (Table 3). An overall score greater than or equal to 3 was highly predictive of a clinical diagnosis of $\mathrm{ABE}$, with sensitivity of $90.7 \%$, specificity of $97.7 \%$, positive predictive value of $88.9 \%$, and negative predictive value of $98.2 \%$. Fifty (94.3\%) of the 53 infants with $\mathrm{ABE}$ had scores of "2" ("moderate") or "3" ("severe") on at least one subscale (mental status, muscle tone, cry, or eye findings). However, residents had 9 false positives versus 8 for consultants, based on this single criterion. The most consistently detected sign was alteration in muscle tone. Residents scored 48 of 53 (90.6\%) infants with $\mathrm{ABE}$ in the "moderate-to-severe" range; the consultants similarly scored $84.9 \%$ of these infants. Alteration in mental status was a less consistent finding for $\mathrm{ABE}$; residents noted "moderate-to-severe" alterations in mental status for 42 out of the $53(79.2 \%)$ infants with ABE versus 44. $(83 \%)$ noted by the consultants. Alterations in cry were similarly noted by residents and consultants ( 44 and 43 of 53, respectively). Consultants recognized paralysis of upward gaze in 26 (49\%) of the 53 infants with encephalopathy, versus only 19 (35.8\%) that were detected by residents. All infants with eye findings had a diagnosis of $A B E$. However, when eye finding points were subtracted from the BIND-M score, all infants with ABE still had a BIND score of 3 and above.

\section{Risk factors for neonatal jaundice}

A total of 198 records met criteria for additional exploratory analyses. Pediatric consultants made a clinical 
Table 2 Sub-score correlations of BIND-M scores: residents versus consultants

\begin{tabular}{|c|c|c|c|c|c|c|c|}
\hline \multirow{2}{*}{\multicolumn{2}{|c|}{$\begin{array}{l}\text { a: Mental status sub-scores } \\
\text { Weighted Kappa }=0.7692(95 \% \mathrm{Cl}: 0.6977,0.8407)\end{array}$}} & & \multicolumn{5}{|c|}{ Consultants } \\
\hline & & & 0 & 1 & 2 & 3 & Total \\
\hline \multirow[t]{5}{*}{ Residents } & Normal mental status. & 0 & 246 & 11 & 3 & 1 & 261 \\
\hline & Sleepy, Difficult to Awaken for Feeding & 1 & 12 & 10 & 2 & 0 & 24 \\
\hline & Very sleepy; Alternatively very irritable & 2 & 3 & 1 & 27 & 1 & 32 \\
\hline & Semi-Coma; Apnea; Convulsions & 3 & 0 & 2 & 5 & 9 & 16 \\
\hline & Total & & 261 & 24 & 37 & 11 & 333 \\
\hline \multicolumn{3}{|c|}{ b: Muscle tone sub-scores } & \multicolumn{5}{|c|}{ Consultants } \\
\hline \multicolumn{3}{|c|}{ Weighted Kappa $=0.8430(95 \%$ Cl: $0.7809,0.9051)$} & 0 & 1 & 2 & 3 & Total \\
\hline \multirow[t]{5}{*}{ Residents } & Normal muscle tone & 0 & 259 & 7 & 3 & 1 & 270 \\
\hline & Persistent mild hypotonia & 1 & 2 & 7 & 0 & 0 & 9 \\
\hline & $\begin{array}{l}\text { Moderate hypotonia; moderate hypertonia; increasing arching of neck and trunk on stimulation without } \\
\text { spasms of arms \& legs and without trismus }\end{array}$ & 2 & 3 & 3 & 22 & 4 & 32 \\
\hline & $\begin{array}{l}\text { Persistent retrocollis; opisthotonus; crossing or scissoring of arms or legs but without spasms of arms \& legs } \\
\text { and without trismus }\end{array}$ & 3 & 1 & 0 & 3 & 18 & 22 \\
\hline & Total & & 265 & 17 & 28 & 23 & 333 \\
\hline \multicolumn{3}{|c|}{ c: Altered cry sub-scores } & \multicolumn{5}{|c|}{ Consultants } \\
\hline \multicolumn{3}{|c|}{ Weighted Kappa $=0.8139$ (95\% Cl: $0.7321,0.8957)$} & 0 & 1 & 2 & 3 & Total \\
\hline \multirow[t]{5}{*}{ Residents } & Normal cry & 0 & 279 & 3 & 1 & 3 & 286 \\
\hline & High-pitched cry & 1 & 4 & 2 & 1 & 3 & 10 \\
\hline & Shrill cry & 2 & 1 & 0 & 6 & 0 & 7 \\
\hline & Inconsolable crying, or cry weak or absent in child with previous history of high pitched or shrill cry & 3 & 2 & 1 & 3 & 24 & 30 \\
\hline & Total & & 286 & 6 & 11 & 30 & 333 \\
\hline \multicolumn{3}{|c|}{ d: Altered gaze sub-scores } & \multicolumn{5}{|c|}{ Consultants } \\
\hline \multicolumn{3}{|c|}{ Simple Kappa $=0.5802(95 \%$ Cl: $0.4055,0.7549)$} & 0 & 3 & & & Total \\
\hline \multirow[t]{3}{*}{ Residents } & Normal Gaze & 0 & 301 & 12 & & & 313 \\
\hline & Sun-setting; paralysis of upward gaze & 3 & 6 & 14 & & & 20 \\
\hline & Total & & 307 & 26 & & & 333 \\
\hline
\end{tabular}

Table 3 BIND-M score versus consultant diagnosis of acute bilirubin encephalopathy (ABE)

\begin{tabular}{|c|c|c|c|c|c|c|c|c|c|}
\hline \multirow{3}{*}{$\begin{array}{l}\text { Consultant score vs. } \\
\text { consultant diagnosis }\end{array}$} & & \multicolumn{4}{|c|}{ Final diagnosis } & \multicolumn{4}{|c|}{ Test performance } \\
\hline & & \multicolumn{2}{|c|}{$\overline{A B E}$} & \multicolumn{2}{|c|}{ No $A B E$} & \multirow[t]{2}{*}{ Sensitivity \% } & \multirow[t]{2}{*}{ Specificity \% } & \multirow{2}{*}{$\begin{array}{l}\text { Positive predictive } \\
\text { value } \%\end{array}$} & \multirow{2}{*}{$\begin{array}{l}\text { Negative predictive } \\
\text { value } \%\end{array}$} \\
\hline & & TP & FN & FP & $\mathrm{TN}$ & & & & \\
\hline \multirow[t]{13}{*}{ BIND score cut off } & $\geq 0$ & 53 & 0 & 280 & 0 & 100.0 & 0.0 & 15.9 & N/A \\
\hline & $\geq 1$ & 52 & 1 & 33 & 247 & 98.1 & 88.2 & 61.2 & 99.6 \\
\hline & $\geq 2$ & 50 & 3 & 12 & 268 & 94.3 & 95.7 & 80.6 & 98.9 \\
\hline & $\geq 3$ & 48 & 5 & 6 & 274 & 90.7 & 97.9 & 88.9 & 98.2 \\
\hline & $\geq 4$ & 45 & 8 & 5 & 275 & 84.9 & 98.2 & 90.0 & 97.2 \\
\hline & $\geq 5$ & 44 & 9 & 4 & 276 & 83.0 & 98.6 & 91.7 & 96.8 \\
\hline & $\geq 6$ & 40 & 13 & 2 & 278 & 75.5 & 99.3 & 95.2 & 95.5 \\
\hline & $\geq 7$ & 37 & 16 & 2 & 278 & 69.8 & 99.3 & 94.6 & 94.9 \\
\hline & $\geq 8$ & 32 & 21 & 1 & 279 & 60.4 & 99.6 & 96.7 & 93.0 \\
\hline & $\geq 9$ & 26 & 27 & 0 & 280 & 49.6 & 100.0 & 100.0 & 91.5 \\
\hline & $\geq 10$ & 17 & 36 & 0 & 280 & 32.1 & 100.0 & 100.0 & 88.6 \\
\hline & $\geq 11$ & 11 & 42 & 0 & 280 & 20.8 & 100.0 & 100.0 & 87.0 \\
\hline & $\geq 12$ & 2 & 51 & 0 & 280 & 3.8 & 100.0 & 100.0 & 84.6 \\
\hline
\end{tabular}


diagnosis of ABE in 28 (14.1\%) of these 198 infants. Peak serum bilirubin concentrations were almost twice as high in infants with $\mathrm{ABE}$ compared to those without $\mathrm{ABE}$, and peak bilirubin $>15 \mathrm{mg} / \mathrm{dL}$ was associated with a tenfold OR for ABE (Table 4). Sixty-nine percent of infants were term ( $\geq 38$ weeks), with a mean estimated gestational age of 37.7 (2.7) weeks, and $82.3 \%$ were born either at a clinic or in a hospital. The mean age at the time of BIND-M examination was 124 (74) hours; the mean infant weight at the time of examination was 2751 (725) grams. In infants with a clinical diagnosis of $\mathrm{ABE}$, the mean postnatal age at examination was higher than in infants without ABE but not statistically significant ( $\mathrm{p}=0.053$ ). Additionally, gestational age at birth, birth weight, weight at examination and the proportions of infants with $\mathrm{ABO}$ and $\mathrm{Rh}$ blood incompatibilities did not differ significantly between the groups.

One hundred seven of the jaundiced infants were evaluated for sepsis. Among these, sepsis was diagnosed in $24(26.4 \%)$ of 91 without $\mathrm{ABE}$ and in $12(75.0 \%)$ of 16 with $\mathrm{ABE}(\mathrm{OR}=8.375 ; 95 \% \mathrm{CI}=2.463,28.48)$. Finally, when $\mathrm{ABE}$ was cross-tabulated simultaneously with menthol exposure and G6PD deficiency (Table 4), it was clear that menthol exposure was strongly associated with $\mathrm{ABE}$, but statistically significant only among those whose known G6PD phenotype was unknown $(\mathrm{OR}=25.88$;
95\% $\mathrm{CI}=2.845,235.8)$ or definitely deficient $(\mathrm{OR}=$ 73.94; $95 \% \mathrm{CI}=5.425$, > 999).

\section{Discussion}

Our results have shown that the physical diagnosis of ABE can be facilitated by a modified BIND-M score. The score showed excellent agreement between residents and consultants (weighted Kappa = 0.7969), and appeared to be accurate in predicting infants with $\mathrm{ABE}$ (sensitivity $=90.7 \%$; positive predictive value $=88.9 \%$ ) Thus, BIND-M may be an important yet simple tool to provide a uniform measure of the degree of ABE in clinically jaundiced infants in resource limited settings. Infants with BIND-M scoring less than 3 were extremely unlikely to be diagnosed with clinical ABE (specificity = 97.7\%; negative predictive value $=98.2 \%$ ). Although, a score of 5 had a higher positive predictive value of $91.7 \%$, it is associated with an unacceptable level of false negatives (80\% increase) with an $8 \%$ reduction in sensitivity. While we predicted that a score of 1-4 would be indicative of mild ABE and 5-6 would represent moderate $\mathrm{ABE}$, a threshold as low as 3 is definitely more applicable in this population, possibly as a result of the multiple risk factors and a high prevalence of severe NNJ. It is noteworthy that inter-rater agreement for the upward gaze paralysis sub-score (simple Kappa $=0.5802$ ) was lower

Table 4 Risk factors for acute Bilirubin encephalopathy among Jaundiced Nigerian neonates

\begin{tabular}{|c|c|c|c|c|c|}
\hline \multicolumn{2}{|c|}{ Peak serum bilirubin } & Cases & Controls & Number (\%) & Odds ratio $[95 \% \mathrm{Cl}]$ \\
\hline \multicolumn{2}{|l|}{$<=15.00$} & 3 & 93 & $96(28.8 \%)$ & 1.000 [Referent] \\
\hline \multicolumn{2}{|l|}{ Unknown } & 25 & 110 & $135(40.5 \%)$ & $7.044[2.061,24.07]$ \\
\hline \multicolumn{2}{|l|}{$>15.00$} & 77 & 25 & $102(30.6 \%)$ & $10.06[2.927,34.60]$ \\
\hline \multicolumn{2}{|l|}{ Total } & 105 & 228 & $333(100.0 \%)$ & \\
\hline \multicolumn{2}{|l|}{ Means } & 30.71 & 15.65 & & $P<0.001$ \\
\hline \multicolumn{2}{|l|}{ Gender } & Cases & Controls & Number (\%) & Odds Ratio (95\% Cl) \\
\hline \multicolumn{2}{|l|}{ Male } & 17 & 103 & $120(61.2 \%)$ & $1.089(0.470,2.523)$ \\
\hline \multicolumn{2}{|l|}{ Female } & 10 & 66 & $76(38.8 \%)$ & 1.000 (REFERENT) \\
\hline \multicolumn{2}{|l|}{ Sepsis } & Cases & Controls & Number (\%) & Odds Ratio (95\% Cl) \\
\hline \multicolumn{2}{|l|}{ No } & 4 & 67 & $71(66.4 \%)$ & 1.000 (REFERENT) \\
\hline \multicolumn{2}{|l|}{ Yes } & 12 & 24 & $36(33.6 \%)$ & $8.375(2.463,28.48)$ \\
\hline Menthol & G6PD & Cases & Controls & Number (\%) & Odds Ratio $(95 \% \mathrm{Cl})$ \\
\hline Unexposed & Normal & 1 & 37 & $38(19.2 \%)$ & 1.000 (REFERENT) \\
\hline Unexposed & Unknown & 10 & 63 & $73(36.9 \%)$ & $5.868(0.722,47.66)$ \\
\hline Unexposed & Deficient & 3 & 17 & $20(10.1 \%)$ & $6.524(0.632,67.34)$ \\
\hline Unknown & Normal & 1 & 10 & $11(5.6 \%)$ & $3.697(0.212,64.42)$ \\
\hline Unknown & Unknown & 1 & 25 & $26(13.1 \%)$ & $7.120(0.936,54.18)$ \\
\hline Unknown & Deficient & 1 & 6 & $7(3.5 \%)$ & $6.162(0.338,112.2)$ \\
\hline Exposed & Normal & 0 & 0 & $0(0.0 \%)$ & 0.000 (incalculable) \\
\hline Exposed & Unknown & 7 & 10 & $17(8.6 \%)$ & $25.88(2.845,235.8)$ \\
\hline Exposed & Deficient & 4 & 2 & $6(3.0 \%)$ & $73.94(5.425,>999)$ \\
\hline
\end{tabular}


than that for the altered mental status (weighted Kappa = 0.7692), altered muscle tone (weighted Kappa $=0.8430$ ), and altered cry (weighted Kappa $=0.81399$ ) sub-scores.

Exchange blood transfusion for severe NNJ entails a significant risk for morbidity. This procedure was quite common in the present study, where $24 \%$ of the infants at four major teaching hospitals in Nigeria had EBT. Even in the most experienced hands, this procedure is not without significant risk from the procedure itself as well as the risks for infections and non-infectious complications $[14,15]$. If effectively used in combination with other modalities including intensive phototherapy, BIND-M is capable of reducing the high rate of needless EBT in newborns without $A B E$ as well as enhancing identification of newborns with mild to moderate $\mathrm{ABE}$, considered to be reversible with appropriate and early interventions.

Glucose-6-phosphate dehydrogenase deficiency is known to be a significant risk factor for severe neonatal jaundice and is common in Nigeria. Testing for G6PD deficiency is not routinely available in health institutions and was only performed in a small subset of infants in the present study. Exposure to mentholated products is known to be a significant risk factor for severe jaundice and $\mathrm{ABE}$ in infants with G6PD deficiency $[16,17]$, and yet was commonly used with the neonates in our study: 1 in 6 infants overall, and 4 in 10 infants with ABE. It is therefore imperative to continue public enlightenment campaigns, at least in Nigeria, to educate the populace, and pregnant women in particular, as to the danger of using these products in the newborn period [17].

Surprisingly, neither ABO incompatibility nor Rh disease was significantly different between the two groups of infants with and without $\mathrm{ABE}$, suggesting that other factors such as dehydration, sepsis and harmful cultural practices may play a more significant role in determining the course and severity of newborn jaundice in this area. Concurrent sepsis has been alleged to be a significant risk factor for ABE among Nigerian neonates [18]. Sepsis usually coexists with exposure to exogenous agents that predispose the G6PD deficient infants to severe $\mathrm{NNJ}$ and $\mathrm{ABE}$.

The primary limitation in the present study is the lack of ABR or MRI to validate the BIND-M score. However, since neither ABR nor MRI is the standard of care in these settings, physicians are quite familiar with the clinical diagnosis of ABE. A subsequent study to validate the BIND-M score with ABR is now ongoing in a children's hospital in Lagos, Nigeria. Another significant limitation is the lack of the full medical history for these infants. However, since this was not the focus of this study it will be desirable for a future study.

\section{Conclusions}

The present study has shown that the use of the BIND-M score among consultant pediatricians and their resident doctors in Nigeria is reliable for identifying infants with the clinical diagnosis of $\mathrm{ABE}$ with acceptable sensitivity and specificity. Validation and further modification of this scoring system could provide a much needed tool for use in population studies in Nigeria and elsewhere to estimate the actual magnitude of ABE-related morbidity and mortality. Such data would support the work of child health advocates to devise solutions to reduce or eliminate this preventable morbidity which has long-term, tragic consequences for the infants, their families and their communities.

\section{Additional files}

Additional file 1: Original BIND score scheme.

Additional file 2: Clinical format for prospective scoring of onset, severity and duration of ABE in clinically Jaundiced infants-modified BIND (BIND-M).

\section{Abbreviations}

ABE: Acute bilirubin encephalopathy; BIND-M: Modified bilirubin induced neurologic dysfunction; G6PD: Glucose-6-phosphate dehydrogenase; SAS: Statistical analysis system; NNJ: Neonatal jaundice; EBT: Exchange blood transfusion; MRI: Magnetic resonance imaging; ABR: Auditory brainstem response; OR: Odds ratio; $\mathrm{Cl}$ : Confidence interval.

\section{Competing interests}

The authors hereby declare that they have no competing interests. The authors also hereby declare that they do not have any financial competing interests.

The authors further hereby declare that they do not have any non-financial competing interests.

\section{Authors' contributions}

PGR had primary responsibility for protocol development, basic data analysis and writing the manuscript. FDG contributed to the protocol development and analysis of the comparison of resident and consultant scoring. He also contributed to editing the manuscript. JAO, GEO and EAA enrolled subjects for the study and taught the BIND scoring in their nurseries. They also contributed to editing the draft manuscript. BOO contributed to the editing of the manuscript for critical intellectual content. TMS assisted in the development of the protocol, initially teaching the BIND scoring technique as well as writing and editing the manuscript. All authors read and approved the final manuscript.

\section{Acknowledgements}

The authors would like to express their thanks to Drs. Lois Johnson and Vinod Bhutani for sharing the BIND and allowing us to modify it. Additional thanks to Dr. Vinod Bhutani of Stanford University, Stanford, CA, USA for his kind suggestions and edits.

This work was supported by a Basic Grant Program award received by Dr. Paula Radmacher (Intramural Grant to PGR). She received a $\$ 10,000$ grant from the School of Medicine, University of Louisville.

\section{Author details}

${ }^{1}$ Department of Pediatrics, University of Louisville School of Medicine, Louisville, KY, USA. ${ }^{2}$ Department of Epidemiology and Population Health, University of Louisville School of Public Health and Information Sciences, Louisville, KY, USA. ${ }^{3}$ Department of Paediatrics and Child Health, Obafemi Awolowo University, Ile-Ife 220005, Nigeria. ${ }^{4}$ Department of Child Health, University of Benin, Benin City, Nigeria. ${ }^{5}$ Neonatal Unit, University of Benin Teaching Hospital, Benin City, Nigeria. ${ }^{6}$ Centre for Healthy Start Initiative, Ikoyi, Lagos, Nigeria. ${ }^{7}$ Center for Global Pediatrics, University of Minnesota, Minneapolis, MN, USA. ${ }^{8}$ Hennepin County Medical Center, Minneapolis, MN, USA. 
Received: 7 November 2014 Accepted: 23 March 2015

\section{Published online: 01 April 2015}

\section{References}

1. Tomashek KM, Crouse CJ, lyasu S, Johnson CH, Flowers LM. A comparison of morbidity rates attributable to conditions originating in the perinatal period among newborns discharged from United States hospitals, 1989-90 and 1999-2000. Paediatr Perinat Epidemiol. 2006;20:24-34.

2. Escobar GJ, Greene JD, Hulac P, Kincannon E, Bischoff K, Gardner MN, et al Rehospitalisation after birth hospitalisation: patterns among infants of all gestations. Arch Dis Child. 2005;90:125-31.

3. The Young Infants Clinical Signs Study Group. Clinical signs that predict severe illness in children under age 2 months: a multicentre study. Lancet. 2008;371:135-42.

4. National Institute for Health and Clinical Excellence. Neonatal jaundice. (Clinical guideline 98) 2010. www.nice.org.uk/CG98.

5. Ip S, Chung M, Kulig J, O'Brien R, Sege R, Glicken S, et al. American academy of pediatrics subcommittee on hyperbilirubinemia. An evidence-based review of important issues concerning neonatal hyperbilirubinemia. Pediatrics. 2004;114:e130-53.

6. Slusher TM, Olusanya BO. Neonatal jaundice in low- and middle-income countries. In: Stevenson DK, Maisels J, Watchko J, editors. Care of the jaundiced neonate. New York, NY: McGraw-Hill; 2012. p. 263-73.

7. Owa JA, Ogunlesi TA. Why we are still doing so many exchange blood transfusion for neonatal jaundice in Nigeria. World J Pediatr. 2009;5:51-5.

8. Ogunlesi TA, Adekanmbi AF, Fetuga MB, Ogunfowora OB. The incidence and outcome of bilirubin encephalopathy in Nigeria: a bi-centre study. Niger J Med. 2007;16:354-9.

9. Ogunfowora OB, Daniel OJ. Neonatal jaundice and its management: knowledge, attitude and practice of community health workers in Nigeria. BMC Public Health. 2006:6:19-23.

10. Johnson L, Bhutani VK, Karp K, Sivieri EM, Shapiro SM. Clinical report from the pilot USA Kernicterus Registry (1992 to 2004). J Perinatol. 2009;29 Suppl 1:S25-45.

11. Smitherman $H$, Stark AR, Bhutani VK. Early recognition of neonatal hyperbilirubinemia and its emergent management. Semin Fetal Neonatal Med. 2006;11:214-24.

12. Johnson LH, Brown AK, Bhutani VK. BIND - a clinical score for bilirubininduced neurologic dysfunction in newborns. Pediatrics. 1999;199(3 part 3):746-7.

13. Shapiro SM. Definition of the clinical spectrum of kernicterus and bilirubininduced neurologic dysfunction (BIND). J Perinatol. 2005;25:54-9.

14. Davutoğlu M, Garipardiç M, Güler E, Karabiber H, Erhan D. The etiology of severe neonatal hyperbilirubinemia and complications of exchange transfusion. Turk J Pediatr. 2010;52:163-6.

15. Behjati SH, Sagheb S, Aryasepehr S, Yaghmai B. Adverse events associated with neonatal exchange transfusion for hyperbilirubinemia. Indian J Pediatr. 2009;76:83-5.

16. Olowe SA, Ransome-Kuti O. The risk of jaundice in glucose-6-phosphate dehydrogenase deficient babies exposed to menthol. Acta Paediatr Scand. 1980;69:341-5

17. Owa JA. The relationship between exposure to icterogenic agents, glucose6-phosphate dehydrogenase deficiency and neonatal jaundice in Nigeria. Acta Paediatr Scand. 1989;78:848-52.

18. Dawodu AH, Owa JA, Familusi JB. A prospective study of the role of bacterial infections and G-6-Pd deficiency in severe neonatal jaundice in Nigeria. Trop Geogr Med. 1984;36:127-32.

\section{Submit your next manuscript to BioMed Central and take full advantage of:}

- Convenient online submission

- Thorough peer review

- No space constraints or color figure charges

- Immediate publication on acceptance

- Inclusion in PubMed, CAS, Scopus and Google Scholar

- Research which is freely available for redistribution 